\title{
Bir Toplumsallaşma Aracı Olarak Yeni Medya: Kuramsal Bir Değerlendirme
}

\author{
Sinem Onar Çambay*
}

Ege Üniversitesi, İletişim Fakültesi, İzmir.

\begin{abstract}
Öz
Günümüzde iletişim alanında yaşanan ve tüm dünyayı saran teknolojik gelişmeler, medya alanında yeni bir oluşuma sahne olmuş bulunmaktadır. Söz konusu oluşum, internet, sosyal ağlar, bloglar ve sosyal medya gibi yeni araçların yeni medya ortamları olarak çağımıza damga vurmasına yol açmış bununla birlikte önemli toplumsal değişim ve dönüşümleri de beraberinde getirmiştir. Sosyal ilişki kurma biçimlerini ve ilişki niteliklerini ciddi bir dönüşüme uğratan yeni medya olgusunun toplumsal yapıyı önemli bir biçimde yeniden şekillendirdiği ve bu yapı içerisinde farklı toplumsallaşma biçimlerinin ortaya çıkmasına yol açtığı dikkat çekmektedir. Bu bağlamda günümüzde tüm dünyayı kuşatan yeni medya ortamları ile toplumlarn giderek bir ă̆ toplumuna benzediği ve söz konusu ağlarla oluşan ilişki kurma pratiklerinin yeni toplumsallaşma biçimleri oluşturduğu gözlenmektedir. Toplumsal olarak kimliğin inşasın sağlayan bir kavram olarak öne çıkan yeni medya, sahip olduğu çeşitlilik, modernlik gibi donanımlarla bireylere, daha zengin ve araştırlabilir bir içerik sağlamakta bu nedenle de önemli bir toplumsallaşma aracı olarak dikkat çekmektedir. Bu noktada vurgulanması gerekli en önemli husus gündelik yaşantımızın her alanına nüfuz etmiş bulunan yeni medya ortamlarının önemli ve yeni bir kamusal alan yarattığ $\imath d \imath$.
\end{abstract}

Anahtar Kelimeler: Medya, Yeni Medya, Toplumsallaşma, Toplumsallaşma Araçları.

\section{New Media as a Tool of Socialization: A Theoretical Review}

\section{Abstract}

Technological developments affecting the whole world in communication area, -have created a new formation in the media. This formation caused new communication tools called inthernet, social networks, bloggs and social media to affect to era. At the same time, important social changes and transformations have occurred. New media transformed the ways social interaction and relationship attributes, significantly reshape to social structure. It has led to the emergence of different forms of socialization. In this context, communities has become an increasingly network society thanks to new media environment. Also these socialization paths have created new ways of socializing forms. New media which is provided the identity formation has equipments, such as diversity and modernity. These provides richer and searchable contents for persons. Therefore, new media draws attention as an important socialization tool. Finally, the most important thing to be expressed that new media environments fully penetrating our daily lives has created a new public space.

Keywords: Media, New Media, Socialization, Tools of socialization.

\section{GİRIS}

Günümüzde tüm dünyayı giderek saran değişim olgusu, medya alanında da son derece önemli dönüşümlere sahne olmakta ve bu dönüşümlerin sonucu olarak özellikle yeni medya ortamlarını toplumsallaşmanın önemli birer aracı konumuna getirmiş bulunmaktadır. Öyle ki, teknolojik gelişmelerin ivme kazandığı günümüz 
dünyası, iletişim alanında yeni toplumsallaşma türlerini de ortaya çıkarmış bulunmaktadır. Yeni teknolojik gelişmeler ile birlikte son yıllara damgasını vuran bir olgu olarak yeni medyanın, toplum içerisinde bireylere farklı paylaşım olanakları sağladığı bu bağlamda da yeni medya ile farklı bir kamusal paylaşım olanakları yaratıldığı dikkat çekmektedir.

Yeni medya ortamlarının işler kıldığı paylaşım odakları aynı zamanda farklı toplumsallaşma biçimlerini de örgütlemekte olup bu toplumsallaşma biçimleri içerisinde dikkat çeken en önemli tür hareketsiz toplumsallaşma olgusu olarak öne çıkmaktadır. Bireyler arasında yüz yüze iletişim kurulmaksızın zaman ve mekan kavramından tümüyle bağımsız interaktif iletişim olanaklarına imkan sağlayan yeni medya ortamları çağa uygun ve farklı bir toplumsallaşma biçimini de örgütlemiş bulunmaktadir.

Çalışmada öncelikle toplumsallaşma olgusuna kavramsal ve kuramsal olarak değinilerek toplumsallaşmanın hangi araçlarla ve nasıl gerçekleştiği açıklanmakta daha sonra bir toplumsallaşma aracı olarak yeni medya kavramı ile yeni medya ortamlarına değinilmektedir.

\section{Kavramsal ve Kuramsal Olarak Toplumsallaşma Olgusu}

Bireyin içinde yer aldığı toplumun mevcut değer ve kurallarının öğrenilmesi süreci olarak tanımlanabilecek toplumsallaşma olgusu, bireylere ait oldukları toplumun bir üyesi olmak için uymaları gerekli davranış kurallarını ve kültürel normları içselleştirmelerini sağlayan bu bağlamda da birey ve toplum bütünleşmesini olanaklı kılan önemli bir toplumsal süreç olarak göze çarpmaktadır.

Çocuk ya da yetişkin bir bireyin içinde bulunacağı sosyal yaşamın gereklerine uygun bir biçimde davranması süreci olarak tanımlanabilecek toplumsallaşma olgusu, iletişim araçları ve kodlarını, ortak yaşam kuralları ile pratiklerini, düşünce tarzlarını içererek topluma entegre olma sürecini ifade eden bir kavram olarak belirginleşmektedir (Bilgin, 2003:351).

Toplumsal düzenin sağlanması ve devam ettirilmesinde önemli bir araç olarak toplumsallaşma, insanlara sosyal deneyimler yoluyla toplumla bütünleşik bir kişilik kazandıran önemli bir süreci ifade etmektedir (Bahar, 2009:71).

Toplumsal ve kültürel olanın tüm nesillere aktarılmasına olanak sağlayan bir süreç olarak toplumsallaşma, hiç bitmeyen dinamik bir yapı olarak dikkat çekmektedir. Bu yapı içerisinde teknoloji olgusu, önemli bir toplumsallaşma aracı olarak konumlanmakta olup bilgi üretmenin ve paylaşmanın bu bağlamda da sosyal yapının hem inşasının hem de şekillenmesinin itici gücü olarak belirginleşmektedir.

Bireyin bir toplumun üyesi ve parçası olarak diğer bireylerle karşılıklı etkileşim kurması süreci olarak öne çıkan toplumsallaşma olgusu, ömür boyu devam eden bir sürece işaret etmektedir.

Toplum içerisinde bireylerin karşılıklı bir biçimde değer yargıları, tutum ve davranışlarını, alışkanlıklarını diğer bireylerle dönüştürmelerine olanak sağlayan bir 
olgu olarak toplumsallaşma, toplumla bütünleşmeyi sağlamsı bakımından önem taşımakta ayrıca toplumsal davranış ve normlara uygun bir biçimde davranarak topluma uyum sağlamayı gerekli kılmaktadır.

Bireyin yalnızca aile, akraba, komşuluk ve okul ilişkilerini değil aynı zamanda ulusun ve toplumun bir üyesi olarak farkındalık sağladığı dinamik bir yapıyı ifade eden toplumsallaşma özellikle yurttaşlık bilincinin fakına varıldığı önemli bir sosyalizasyon süreci olarak öne çıkmaktadır. Söz konusu sürece yönelik vurgulanması gerekli en önemli husus, sürekli aktif olduğu ve ömür boyu süren bir süreç olduğudur.

Toplumda bireye toplumsal olarak kişilik kazandırmayı amaç edinmiş toplumsallaşma olgusu, toplumsal gelişme ve değişme için önemli bir araç olarak öne çıkmaktadır. Bu araç, bireylerin toplum içerisinde diğer bireylerle ilişkilenmesini ve bireylerin bir arada yaşamalarını teşvik etmekte bu bağlamda da toplumsal yaşamı hareketlendirmektedir. Söz konusu hareketlenmenin en önemli sonuçlarından birisi de toplumsal değerlerin gelişmesi ve kültürün gelecek kuşaklara aktarılması, toplumun ve kültürün devamının sağlanması şeklinde öne çıkmaktadır.

Toplumsallaşma süreci içerisinde bireylerin tutum, davranış, değer ve algılarının sürekli olarak değişme uğradığı görülmekte olup bu süreci yönlendiren birçok araç bulunduğu göze çarpmaktadır.

\subsection{Toplumsallaşma Araçları}

Dinamik ve sürekli gelişen bir süreç olarak toplumsallaşma sürecini şekillendiren birçok unsur olmakla birlikte bu unsurları toplumsallaşma araçları olarak tanımlamak mümkün olacaktır.

Toplumsallaşma, bir süreç olarak ailede başlayan, okul, arkadaş grupları ve kitle iletişim araçları etkisiyle devam eden bir özellik göstermekte olup söz konusu dinamikler toplumsallaşma araçları olarak adlandırılmaktadır. Toplumsallaşma sürecinde birey bu araçlar aracılığıyla diğer insanlar ve sosyal gruplarla sağlıklı bir biçimde etkileşim kurmayı öğrenmekte bu sayede toplumun devamı sağlanmaktadır (Erkal, 2000:80-82). Söz konusu araçlar, bireyin yaşadığı toplumun bir üyesi olarak bir kimlik ve toplumsal bir kişilik kazanmasını sağlamaktadır.

Toplumsallaşmanın bir süreç olarak devamını sağlayan araçlar olarak toplumsallaşma araçları, bireyler arasındaki etkileşimi sürekli kılmakta bu bağlamda toplumun ve kültürün devamına hizmet etmektedir. Bu noktada vurgulanması gerekli en önemli husus toplumsallaşmanın gerçekleşmesinde önemli bir rol üstlenmiş bulunan bu araçların hem toplumda anomi gibi durumların oluşumunu engellediği hem de değer kazanma, sosyal rollere uygun davranmayı öğrenme gibi önemli toplumsal davranışları özümsemeyi teşvik ettiğidir.

Bireyin toplumsal olanla bütünleşmesini sağlayan toplumsallaşma araçları, aile, okul, arkadaşlık grupları, sosyal ve kültürel topluluklar, din ve medya gibi aygıtlar şeklinde belirginleşmekte olup söz konusu araçlar toplumsallaştırıcı faktörler olarak adlandirılmaktadir. 
Bireyin yaşamında ilk toplumsallaştırıcı araç olarak öne çıan aile kurumu, toplumsallaşmanın başarılı biçimde gerçekleşmesinin ilk ve en önemli basamağı şeklinde belirginleşmektedir. Bireyin toplumla bütünleşip topluma uyum sağlaması öncelikle bu kurumdaki rol ve davranışlara bağlı bulunmaktadır.

Bireyin toplumsal yaşamina yön verip onu toplumla bütünleştiren önemli diğer bir araç da din kurumu şeklinde göze çarpmakta olup bu aracın özellikle ahlaki olarak topluma adaptasyonu sağladığı görülmektedir.

Toplum içerisinde bireylerin hem okuma, yazma ve konuşma yeteneklerini geliştirip onları toplumla bütünleştiren hem de toplumsal sitemin değer yargıları ve davranışlarını öğrenmesini sağlayan diğer bir toplumsallaşma aracı da eğitim olarak öne çıkmaktadır.

Toplumda toplumsallaşmanın ne yönde gerçekleşeceğine katkıda bulunarak toplumsal rol ve modellerin oluşum şeklini belirleyen önemli diğer bir toplumsallaşma aracı da arkadaş grupları olarak dikkat çekmektedir.

Ayrıca bireylerin toplumsal ve duygusal olarak yeteneklerini geliştirerek toplumsal olanla bütünleştiren diğer toplumsallaşma araçları olarak spor faaliyetleri ve çalışma ortamı gibi araçlar da öne çıkmakta olup bu araçların önemli toplumsal davranış ve normların kazanılmasında çok etkili oldukları görülmektedir.

Bireyin toplumla bütenleşmesini sağlayan, deneyim, tutum ve dünya görüşlerini etkileyen önemli diğer bir toplumsallaşma aracı da gazete, dergi, televizyon ve radyo gibi çok geniş içerikli bir araç olan medya şeklinde belirginleşmektedir.

Toplumsallaşmanın uygun ve başarılı bir biçimde gerçekleşmesini sağlayan bu araçlar, bireyin toplumla başarılı bir biçimde bütünleşmesini teşvik ettiğinden sorunsuz ve bilinçli bireylerin yer alacağı sağlıklı bir toplum yapısının ve kamusal düzenin inşasında önemli bir rol üstlenmiş bulunmaktadır. Çünkü söz konusu araçlar, bireye toplumun kendisinden beklediklerini uygulama ve içselleştirme zorunluluğunu kazandırmaktadır.

Günümüzde toplumsallaşma sürecini yönlendiren en önemli araçlardan birisi de güçlü bir kamuoyu oluşturucu gücü bulunan yeni iletişim teknolojileri ile öne çıkan yeni medya araçları şeklinde belirginleşmektedir.

\section{Yeni Medya Kavramı ve Özellikleri}

Günümüz iletişim çağında öne çıan bir kavram olarak yeni medya, farklı ses, renk ve düşüncelerin tüm dünya dahilinde iletişime geçmesine olanak sağlayan alternatif bir medya anlayışı olarak belirginleşmektedir (Karaismailoğlu, 2014: 302). Geleneksel medyadan tümüyle farklı bir nitelik taşıyan bu olgu günümüzde ortaya çıkan yeni iletişim teknolojileri ve uygulamalarını ifade eden ve iletişim sürecini hızlandıran bir kavram olarak dikkat çekmektedir.

İçinde bulunduğumuz iletişim çağına damgasını vuran ileri teknolojiler ve beraberinde bilgisayarlar zaman ve mekan kavramlarını önemsiz kılmakta dünyanın farklı yerleriyle iletişimi olağan hale getirmektedir (Dolgun, 2005:128). Söz konusu 
olağanlık, teknolojik gelişmelerin iletişim süreçlerinde aktif olarak kullanımı sonucunu doğurmakta bu bağlamda yeni medya olgusu iletişimin temel aracına dönüşmüş bulunmaktadir.

1990'lı yıllardan itibaren önem kazanmış ve günümüzde iletişim teknolojilerindeki gelişmelerle birlikte tüm hayatımıza nüfuz etmiş bir olgu olarak yeni medya, toplumsal olarak kimliğin inşasını sağlayan önemli bir kavram olarak öne çıkmaktadır (Alioğlu, 2011: 49-52). Söz konusu önem bu aracın sahip olduğu çeşitlilik, modernlik gibi donanımlara sahip olmasından kaynaklanmaktadır. Bu donanımlar bireylere, daha zengin ve araştırılabilir bir içerik sağlamakta ve ifade olanağı tanımaktadır.

Dijital bir kodlama sistemine sahip, modülerlik ve hipermetinsellik özellik taşıyan, bireylerin karşılıklı bir biçimde etkileşime olanak sağlayan aktif bir iletişim alanı olarak tanımlanabilecek yeni medya, günümüz enformasyon çağının en temel aracı olarak öne çıkmaktadır (Yengin, 2012: 128-132). Söz konusu araç, gündelik yaşantımızın her alanına nüfuz ederek sosyal, ekonomik ve kültürel yaşantımızı tümüyle biçimlendirmektedir.

Yeni iletişim teknolojileri ile hayatımıza damgasını vurmuş bir kavram olarak yeni medya, bilgisayar ağ yapıları arasında iletişim kurmaya yarayan yazılımlara dayanmakta olup erişilebilirlik olanaklarını yükseltip toplum içerisinde etkileşim kurma yeteneğini artıran bir araç olarak öne çıkmaktadır (Köseoğlu, 2012: 433-435). Söz konusu araç, toplumsal yaşamı tümüyle biçimlendirmekte farklı kamusal ortamların oluşmasına aracılık etmektedir.

Çoklu ortam özelliğine sahip yeni medya, internet aracılığıly yapılan iletişim olanaklarını ifade etmekte olup geleneksel medyanın gösterdiği monolog yapıyı ortadan kaldırarak süreksiz ve kesintisiz bir iletişime olanak sağlamaktadır. Bu bağlamda herkese ulaşma imkanı sağlayan bir araç olarak yeni medyanın önemli ve alternatif bir medya aracına dönüştüğü görülmektedir. Söz konusu önem yeni medyayı, demokrasinin yasama, yürütme ve yargıdan sonra dördüncü kuvveti olarak konumlanmasına neden olmuş bulunmaktadır.

Siyasal, ekonomik ve toplumsal hayata katılım yollarını çeşitlendiren bir kavram olarak yeni medya, bireylerin toplum hayatının her bir alanına kolaylikla girmelerini sağlayacak önemli dijital olanaklar sağlayan bir araç olarak dikkat çekmektedir (Akca, 2014: 18- 20). Bu araç önemli ve yeni bir kamusal alan yaratmakta olup iletişim açısından yeni ortamlar yaratmaktadır.

İnternet, sosyal medya, bloglar, sosyal ağlar gibi yeni medya ortamları, hem sosyal ilişki biçimlerini hem de niteliğini değiştirmekte bu bağlamda da toplumsal hayatı yeniden şekillendiren önemli araçlar olarak öne çıkmaktadır. Söz konusu araçlar ağlar yoluyla toplumu bir ağ toplumuna dönüştürmekte ve bu ağlar ile önemli toplumsal dönüşümleri sağlamaktadır. 
Sağladığı sosyal ağlar ve olanaklar ile hayatımıza damgasını vuran yeni medya olgusu, bireylerin toplumsal olay ve olgular etrafında örgütlenme imkanlarını artırmakta bu nedenle de önemli bir toplumsallaşma aracı olarak öne çıkmaktadır.

\section{Bir Toplumsallaşma Aracı Olarak Yeni Medya}

Günümüzde tüm dünyayı giderek etkisi altına almış bulunan teknolojik evrim, toplumsallaşma araçlarını da değişime uğratmış bu bağlamda toplumsallaşmanın önemli bir aracı olarak yeni medya olgusunu öne çıarmıştır. Yeni medya, ses ve görüntünün eş zamanlı iletimini kolaylaştırıp zaman ve mekan kavramını tümüyle yok etme işleviyle toplumsallaşmanın ortamsızlaşmasını sağlamakta bu yönüyle bireylerin kendilerini dışa vurmalarının ve kendilerini ifade etmelerinin önemli bir aracına dönüşmüş bulunmaktadır (Aslan, 2008:220).

Toplum içinde bireyler arasında karşılıklı bir biçimde bilginin elde edilmesinde, toplanmasında, işlenmesinde ve aktarılmasında etkileşime olanak sağlayan yeni medya kavramı, internet, oyun konsolları, tabletler, mobil telefonlar, bloglar, sosyal medya gibi yeni iletişim teknolojilerini içermektedir. Söz konusu yeni medya ortamları, toplumsal ve kültürel olguların şekillenip biçim almasında önemli bir araç olarak konumlanmış bulunmaktadır.

Yeni medya, sosyalleşmenin temel aracına dönüşmüş bulunmakla birlikte toplumun sosyal kaynaklarını geliştirmekte ancak bu gelişimi daha çok sanal olarak sağladığından toplumsallaşma anlamında önemli bir sorun yaratmaktadır ( Sütçü; Algül, 2013: 61).

Yeni medya ortamları toplum içindeki bireyleri nesnel ve sosyo kültürel olarak kuşatmakta bu bağlamda da toplumsallaşma anlayışını da değiştirmektedir (Yengin, 2012: 345-346). Bu bağlamda sürekli bir değişim ve gelişim içerisinde bulunan yeni medyanin bireylerin hem toplum hem de diğer bireylerle olan ilişkilerinde sürekli bir dönüşüm yarattığı göze çarpmaktadır.

Sürekli olarak gelişen internet ve mobil teknolojisiyle ortaya çıkan bir medya platformuna işaret eden bir kavram olarak yeni medya, internetten bloglara, multimediadan bilgisayar oyunlarına, cep telefonlarından web sitelerine ve e-postalara kadar çok geniş içerikli bir kavramı ifade etmektedir (Akyüz, 2010: 177). Yeni medyanın söz konusu ortamları, iletişim çağına uyum sağlamanın önemli birer aracı olarak öne çıkmaktadır.

Önemli bir toplumsallaşma aracı olan internetin toplumsallaşmanın en önemli araçları olan sosyal paylaşım ağlarını kullanılabilir kılma ve bu sayede de toplumsal olanın geniş kitlelere aktarımını maksimize etme gibi önemli işlevler üstlendiği göze çarpmakla birlikte özellikle küresel olana uyum sağlamayı teşvik ettiği görülmektedir.

Yeni medya araçları, bireyleri hem bireyselleştirmekte hem de sanal alemde yeni bir biçimde toplumsallaştırarak hareketsiz toplumsallaşmaya olanak sağlamaktadır (Binark, 2007: 23). Öyle ki yeni medyanın özellikle taşınabilir olma özelliği zamansal ve mekansal sorunları ortadan kaldırdığından her zaman ve her yerde olma donanımı ile yeni bir temsil sistemi yaratmaktadır. Yeni medya ortamları 
söz konusu sistemde toplumda etkileşimi sağlayan ve toplumsallaşmayı yönlendiren temel araçlar olarak konumlanmaktadır.

Yeni medya ortamları, sahip oldukları donanımlarla bireylere toplumsal sorun ve olaylara anında tepki vermelerine ve örgütlenmelerine imkân sağlamaktadır ( Şener, 2013: 255).

Diğer bir ifadeyle her an ve her yerden karşılıklı etkileşim olanağı sağlayan yeni medya, enformasyon akışının kesintisiz hale gelmesini sağlamakta bu yönüyle toplumsallaşma açısından önemli bir araca dönüşmektedir. Bu noktada vurgulanması gerekli en önemli husus, yeni medya ile dokunmatik bir toplumsallaşma türünün ortaya çıktığı sanal ve hareketsiz bir toplumsallaşmanın gerçekleştiğidir.

Birer hareketsiz toplumsallaşma aracı olarak öne çıkan yeni medya ortamları, yeni toplumsal ilişkilere olanak sağlamakta, yeni arkadaşlıkların kurulmasına, mevcut arkadaşlarla iletişime ve her türlü bilgi ve deneyim alışverişine imkan tanımaktadır.

Yeni medya ile bireyin toplumsal ve siyasal olayları izleme, bu olaylara ilgi duyma, önemseme ve harekete geçme gibi toplumsallaşmanın önemli boyutlarının işlevsel kılındığı ve sürekli gelişen teknolojiyle bu donanımların ivme kazandığ görülmektedir.

Yeni medya ile dijital teknolojiye dayalı bir toplum oluştuğundan, toplumsallaşmanın araçları da değişmekte dijital bir toplum oluşmakta, bireylerin ve toplumun düşünce biçimleri değişmektedir. Söz konusu değişim, bireyleri oturdukları yerden toplumsallaştırmaya yönlendirmektedir (Yengin, 2012: 92-97).

Yeni medya ortamları, etkileşim özelliği nedeniyle toplumsal bir teknoloji olarak dikkat çekmektedir (Timisi, 2003: 135). Öyle ki bu ortamlar, küresel dünya ölçeğinde büyük kitlelere kolaylıkla ulaşabildiğinden hem etki düzeyi artmakta hem de toplum içinde bireylerin düşünce, algı, tutum ve fikirlerini yönlendirmektedir. Bu bağlamda yeni medya ortamlarının toplumsallaşmada itici bir güç olarak konumlandığını söylemek doğru olacaktır.

Msn Messenger, Windows Messenger, Skype gibi iletişim programları ile YouTube gibi video paylaşım siteleri, Facebook, Ttwitter gibi sosyal ağlar günümüzde toplumsallaşmanın önemli birer aracı olarak konumlanmakta olup alternatif bir kamusal alan yaratmış bulunmaktadır (Odabaşı, 2010: 265-266). Söz konusu alan yeni medya ile genişlemekte ve bireylere katılım imkânlarını artırarak temsiliyet açısından önemli avantajlar sağlamaktadır. Bu bağlamda yeni medyanın özellikle toplumda bastırılmış grupların, sesini duyuramayanların öne çıkma ve sesini duyurma aracı olduğunu söylemek yanlış olmayacaktır.

Zaman ve mekan kavramını tümüyle ortadan kaldıran yeni medya ortamları sürekli gelişen internet teknolojisi ve beraberinde sosyal medya imkanlarıyla bireylerin aktif birer toplum üyesi ve yurttaş olma yolunda önemli adımlar atmalarını kolaylaştırmakta bu bağlamda da toplusallaşmanın itici gücü olarak konumlanmaktadır. Facebook, Twitter üzerinde yazılan siyasi yazılar, atılan tweetler, tıklanan toplumsal içerikli kampanyalar söz konusu durumu özetler niteliktedir. 
Yeni medyayı toplumsallaşmanın önemli bir aracı olarak konumlandıran diğer bir donanım da, söz konusu ortamların günlük yaşam pratiklerinde birey ve topluluklar için kendini ifade etme ve kimliklenme işlevi taşıması olarak göze çarpmaktadır (Doğu ve Diğerleri, 2014: 98).

Öyle ki yeni medya ortamlarının bireyleri aktif birer birey ve vatandaş olma anlamında harekete geçirdiği bu bağlamda da interaktif iletişim olanaklarıyla bulundukları yerden hiç kalmaksızın dünyanın öbür ucuyla iletişim kurup kendilerini ifade etmelerine olanak sağladığ1 görülmektedir. Bu bağlamda tüm günlük yaşam pratiklerimizin sanal ortama aktarılmasına aracılık eden yeni medya toplumsallaşmasının önemli bir toplumsallaşma türü olduğu göze çarpmaktadır.

Yeni medya ortamları ile bireylerin farklılıklarla bir arada yaşamalarına farklı birey ve kültürlerle bütünleşmelerine imkan tanıyan bir toplumsallaşma pratiği teşvik edilmekte olup bunun için yeni kamusal alanlar yaratılmaktadır.

Yeni medya toplumsallaşması bireylerin toplumsal yaşama bulundukları yerden katılmalarını ve toplumsal sitemin zaman ve mekan kavramı olmaksızın işleyişini sağlayan önemli bir süreci ifade etmekte olup önemli sayıda toplumsal grupların oluşmasını sağlamaktadır. Bu bağlamda toplumsallaşmanın ayrıcalıklı bir aracı olarak yeni medyanın demokratik olabilmenin öne koşulu olan katılmayı işlevsel kılarak hem bireyleri toplumla bütünleştirdiği hem de siyasal ve toplumsal yaşamı yeniden biçimlendirdiği gözlenmektedir.

Bir toplumsallaşma aracı olarak yeni medya, bireylere kendilerini ifade edebilmelerinde önemli bir ortam sağlamakta ve bu ortamı özgür, eşit, şeffaf bir biçimde yapılandırmaktadır. Bu bağlamda yeni medyanın toplumsal standartların benimsenerek bireylerin toplumsal olaylara katılma ve toplumsal olana entegre olma sürecinde önemli bir araç olarak konumlandığını söylemek doğru olmakla birlikte bu süreci yönlendirecek en önemli unsur olarak teknolojiye erişim olanakları öne çıkmaktadır.

Öyle ki dünyanın birçok ülkesinde teknolojik imkanlarının yetersizliği hatta aynı ülke içinde bile teknolojiye erişim uçurumları bu toplumsallaşma aracının işlevini örselemektedir. Ayrıca, bireylerin hareketsiz yığınlar halinde toplumsallaşmasına aracılık eden yeni medyanın bu toplumsallaşma türü ile her ne kadar katılımı artırdığ izlenimi yaratılsa da aslında bir bakıma gözetim toplumu ve iktidar tarafından kayıt altına alınmış toplum yığınlarının yaratıldığı da vurgulanması gerekli önemli bir husus olarak karşımıza çıkmaktadır.

George Orwell'in da belirttiği gözetim olgusu, yeni medya ortamlarının sağladığ1 toplumsallaşma biçimi olan hareketsiz toplumsallaşma ile günümüz dünyasında önemli bir güce ulaşmış bulunmakla birlikte bu gücün yeni medya ortamları ile öne çıkan arzulanan teşhircilik olgusu ile daha da önemli hale geldiği gözlenmektedir. O halde yeni medya ortamları ile öne çıkan bir kavram olarak hareketsiz toplumsallaşmanın teşhirci bir kültürü meşrulaştıran önemli bir kamusal 
alan yarattığı ve bu alanda görünebilir ve erişilebilir olmayı gerekli kıldığı göze çarpmaktadır.

Yeni medya toplumsallaşmasına yönelik dikkat çekilmesi gerekli diğer bir eleştirel husus da hareketsiz toplumsallaşmaya olanak tanıyan yeni medya araçlarının her ne kadar bilgi paylaşımı açısından avantaj yaratsa da toplumsallaşmanın önemli bir yapı taşı olan birlikte olma ve yüz yüzelik süreçlerini örselediği şeklinde öne çıkmaktadır. Söz konusu olumsuzluk toplumsallaşmanın özellikle dokunma ve temas boyutlarında sorun yaşanarak mutsuz ve yalnız bireyler bu bağlamda da şizofrenik bir toplum problemlerine yol açabilmektedir.

Yeni medya ortamları ile sağlanan toplumsallaşma biçimleri, aşırı izole olmuş ortamlarda yarattıkları toplumsallaşma deneyimiyle karşılıklı iletişim kurma zorunluluğunu yok ederek toplumsal uyumu da zorlaştırmakta toplumsallaşmanın temel donanımı olan duygusal bağ kurma zorunluluğunu örseleyerek yetersiz toplusallaşmaya yol açmaktadır.

Öyle ki, yeni medya toplumsallaşması, bilginin uluslararasılaşması, kolayca değiş tokuşu ve erişilebilirliği açısından avantaj yaratırken iletişimin kalitesini örselemekte bu bağlamda anti-sosyal davranış bozukluğu, a- sosyal bir toplum oluşmasına yol açabilmektedir. İnsan ilişkilerindeki yüz yüzelik ve temasın sağlıklı bir birey ve mutlu bir toplumun oluşumundaki önemi dikkate alınacak olursa yeni medya toplumsallaşmasının beraberinde getireceği toplumsal problemler açıkça görülecektir. Söz konusu problemlerin günümüz toplumlarında dikkat çeken belli başlı örnekleri yok olmuş aile içi iletişimler, boşanma oranlarının artması, ağlara ve ekranlara bağımlı bireyler şeklinde öne çıkmaktadır.

Sonuç olarak yeni medya ortamları ile ortaya çıkan yeni toplumsallaşma biçimlerinin zaman ve mekan unsurlarından bağımsız farklı ve yeni kamusal alanlar yaratarak bilgi ve iletişim açısından önemli avantajlar sağladığı ancak toplumsallaşmanın en önemli aşamaları olan yüz yüzelik, temas gibi unsurları örselediği dikkat çekmekte olup neticede toplumsallaşma açısından yalnızlığa itilmiş bireyler yarattığı göze çarpmaktadır. Çünkü toplumsallaşmanın bir aracı olarak yeni medya, yüz yüze olmadığı için toplumsallaşmanın deneyim olarak başarısız yada eksik gerçekleşmesine neden olarak toplumsal olarak bunalımın artmasına ve sapkın davranışların ortaya çıkmasına yol açabilmektedir.

\section{SONUÇ}

Günümüzde yeni medya ortamları ile ilişki biçimleri değişmekte olup bu dönüşüm süreci içerisinde birey ve toplum da değişime uğramakta sonuçta bu değişimler toplumsallaşma biçim ve araçlarını da değiştirmiş bulunmaktadır. Bu bağlamda yeni medya araçlarıyla ortaya çıkan yeni ilişkilenme biçimlerinin, toplumsallaşma süreci açısından önemli dönüşümleri de beraberinde getirdiği dikkat çekmektedir.

Birer hareketsiz toplumsallaşma aracı olan yeni medya ortamlarının yeni toplumsal ilişkilere olanak sağlayarak yeni sosyal ilişkilerin kurulmasına imkan 
tanıdığı ayrıca bireylere toplumsal ve siyasal olayları izleme, bu olaylara ilgi duyma, önemseme ve harekete geçme gibi toplumsallaşma alanlarında önemli işlevler üstlendiği görülmektedir.

Ayrıca önemli bir toplumsal teknoloji olarak dikkat çeken yeni medya ortamları, toplum içinde bireylerin düşünce, alg1, tutum ve fikirlerini yönlendiren bu bağlamda da toplumsallaşmada itici bir güç olarak konumlanan araçlar olarak öne çıkmaktadır.

Yeni medya ortamlarıyla ortaya çıkan yeni toplumsallaşma biçiminin hızlı bilgi paylaşımı ve karşılıklı etkileşim açısından önemli imkanlar sağladığı ancak yüz yüze iletişim, dokunma ve hissetme kültürüne dayalı ilişki kurma biçimleri açısından eksik ve başarısız bir toplumsallaşmaya neden olduğu ve toplumsal olarak önemli sorunlar yarattığı göze çarpmaktadır.

Yeni medya toplumsallaşmasının doğurduğu en önemli sorun olarak yabancılaşmış bir toplum yapısı dikkat çekmekte olup sosyalleşme alanında toplumsallaşmaktan daha çok yalnızlaşan ve bireyselleşen bir toplumun varlığı dikkat çekmektedir. Sonuçta ortaya çıkan toplumsallaşma türü, yoğun bilgi içerisinde sanal ortamda yolunu kaybetmiş mutsuz bir toplum yapısı inşa etmektedir.

\section{KAYNAKÇA}

Akca, E. B. (2014). Demokratik Katılım Bağlamında Yeni Medya ve Dijital Yurttaşlık. Yeni Medya, Pratikler, Olanaklar. Ed: Emel Baştürk Akca. Kocaeli: Umuttepe Yayınları.

Akyüz, A. (2010). Yeni Medya Uygulamalarında Bütünleşik İletişim ve Reklamlarda Ünlü Kullanımı Stratejisi. İkinci Medya Çağında İnternet. Der: Filiz Aydoğan, Ayşen Akyüz İstanbul: Alfa Yayıncilik.

Alioğlu, N. (2011). Yeni Medya Sanatı ve Estetiği. İstanbul: Papatya Yayıncılık.

Aslan, K. (2008). Değişen Teknolojiler ve Habercilikte İstihbarat. İstanbul: Anahtar Kitaplar Yayınevi.

Bahar, H. İ. (2009). Sosyoloji. Ankara: USAK Yayınları.

Bilgin, N. (2003). Sosyal Psikoloji Sözlüğü, Kavramlar, Yaklaşımlar. İstanbul: Bağlam Yayınları.

Binark, M.( 2007). Yeni Medya Çalışmalarında Yeni Sorunlar ve Yöntem Sorunu. Yeni Medya Çalışmaları. Der: Mutlu Binark, Ankara: Dipnot Yayınları.

Doğu, B., Özçetin, B., Bayraktutan, G., Binark, M., Çomu, T. ve diğerleri. (2014). Siyasetin Yeni Hali Vaka-i Sosyal Medya. İstanbul: Kalkedon Yayınları.

Dolgun, U. (2005). Enformasyon Toplumundan Gözetim Toplumuna. Ankara: Ekin Kitabevi.

Erkal, M.E. (2000). Sosyoloji. İstanbul: Der Yayınları.

Karaismailoğlu, E. (2014). İnsanlık Toplumu Eski Medya Köleliğinden Dijital Medya Efendiliğine Geçebilecek Mi?. Dijital Panorama. Ed: Z. Beril Akıncı Vural, Ankara: Ütopya Yayıncılık 
Köseoğlu, Ö. (2012). Halkla İlişkilerde Yeni Medyanın Kullanımı. Stratejik Halkla İlişkiler Yönetimi, Araştır, Planla, Uygula, Değerlendir. Der: Alin Göztaş, Füsun Topsümer. Ankara: Seçkin Yayıncılık.

Odabaşı, H. F. (2010). Bilgi ve İletişim Teknolojileri Işığında Dönüşümler. Ankara: Nobel Yayınları.

Sütcü, C. S., Algül, A. (2013). Teknolojinin Toplum Üzerindeki Etkisi Açısından İnternetin Kısıtlı Sosyal Çevresi Üzerine Bir Araştırma. Yeni Medya'da Demokrasi. Ed: And Algül, Neda Üçer. Konya: Literatürk Yayınları.

Şener, G. (2013). Toplumsal Mücadele Alanı Olarak Sosyal Medya. Sosyal Medya ve A $\breve{g}$ Toplumu: II: Kültür, Kimlik, Siyaset. Ed: Can Bilgili, Gülüm Şener, İstanbul: Reklam Yaratıcıları Derneği Yayınları.

Timisi, N. (2003). Yeni İletişim Teknolojileri ve Demokrasi. Ankara: Dost Kitabevi Yayınları.

Yengin, D. (2012). Yeni Medya ve Dokunmatik Toplum. İstanbul: Derin Yayınları.

Yengin, D. (2012). Yeni Medyaya Eleştirel Bakış. Yeni Medya Ve... Ed: Deniz Yengin. İstanbul: Anahtar Kitaplar Yayınları.

Yengin, D. (2012). Sosyal İletişim Aracı Olarak Akıllı Telefonların Oluşturduğu Uygulama Toplumu Olgusu: WhatsApp Uygulaması. Sosyal Medya Akademi. Ed: Tolga Kara, Ebru Özgen. İstanbul: Beta Yayınları. 